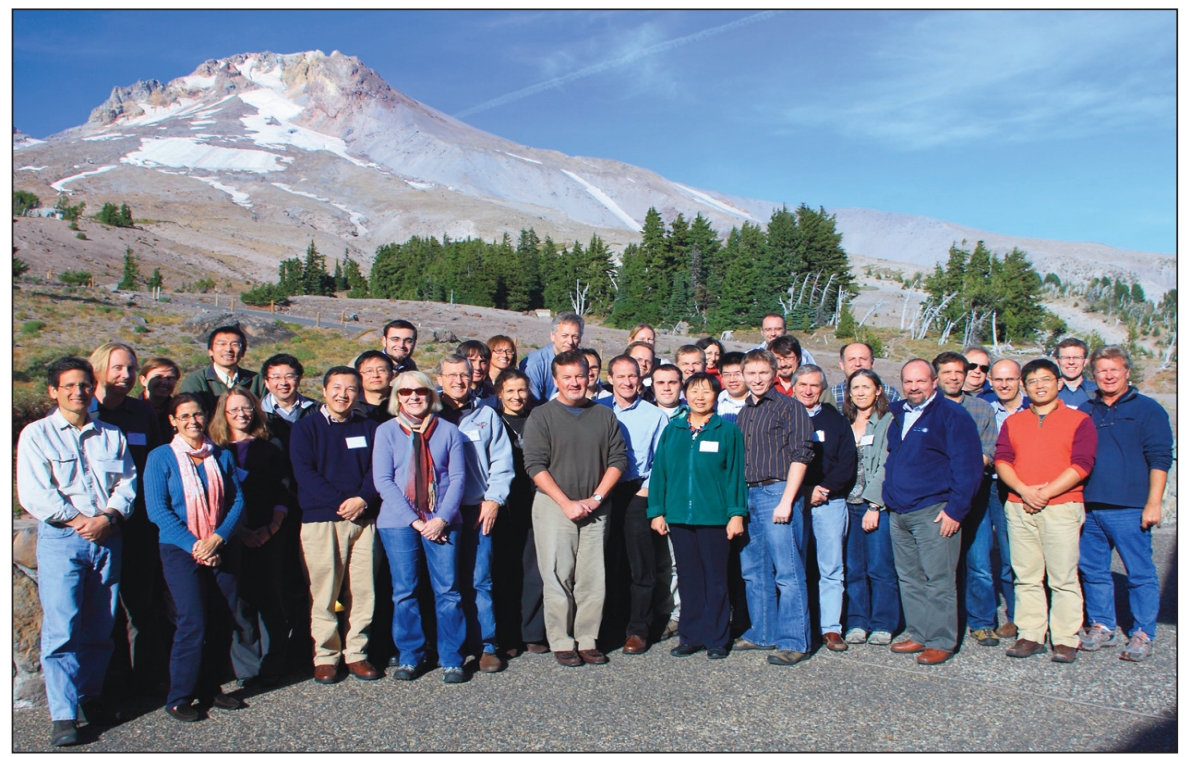

Figure 1: SynTraCE-21 meeting participants in the foreground, Mount Hood in the background.

model simulations. The first international SynTraCE-21k workshop was supported by PAGES, NOAA, and the US Department of Energy, and attracted more than 40 participants from around the world with expertise from terrestrial and marine paleoclimatology to climate modeling.

The first day began with a review of two previously held pilot workshops, which focused on marine and terrestrial records (held in Madison August 2008, and Boulder August 2009). Following this, the focus turned to an update of the meltwater history, which is the most uncertain component of climate forcing in the last deglaciation. The rest of the day was devoted to preliminary model-data comparisons in three models, two coupled general circulation models (CCSM3 and HadCM3) and a climate model of intermediate complexity (ECBilt). These transient simulations mark a new era beyond the "snapshot" studies on "time-slice" climate in paleoclimate model-data comparison because they allow for a direct comparison of time series between the model and data. The studies presented ranged from the evolution of monsoons and global surface climate to regional abyssal circulation variability, showing the great potential of these transient simulations for model-data comparison.

Transient simulations provide an unprecedented opportunity to the paleoclimatology community for modeldata comparison and for improved understanding of climate evolution and abrupt climate change. As a result, it has become critical to develop a major data synthesis to better characterize the global climate variability and to compare with the new generation of transient model simulations.

The second day focused on the terrestrial proxies, with synthesis discussions of lake sediment records, including pollen and charcoal data, ice cores and speleothems. A special session was also arranged to discuss several model-data comparison strategies, including both forward and inverse modeling. The third day was devoted to marine proxies. Reconstructions of the character of the deep and intermediate waters with sedimentary isotopes studies were described. Finally, surface ocean proxies for sea surface temperature and salinity were discussed. Each day ended with an open discussion on the major topics of the day.

The presentations on each major proxy provided a great learning opportunity to all the participants, greatly promoting the interdisciplinary approach towards a multi-proxy data synthesis. To examine model robustness, the meeting participants also recommended coordinated modeling activities among the different research groups. To better assess modelmodel differences and climate sensitivities to external forcing, notably to meltwater forcing, while allowing for flexibility for such long simulations, one strategy proposed was to design common standard sensitivity experiments for different models. Finally, given the large amount of model data, a coordinated model data distribution was also discussed. The workshop participants agreed that the next meeting would be held in the summer of 2012. This workshop will focus on several key topics using an interdisciplinary synthesis approach. Notably, the topics will include the meltwater history and sea level reconstructions for the deglaciation, climate and terrestrial ecosystem in the North American region, and tropical hydrology.

\title{
The $3^{\text {rd }}$ PAGES Past Interglacials workshop
}

\author{
Palisades, New York, USA, 20-22 October 2010
}

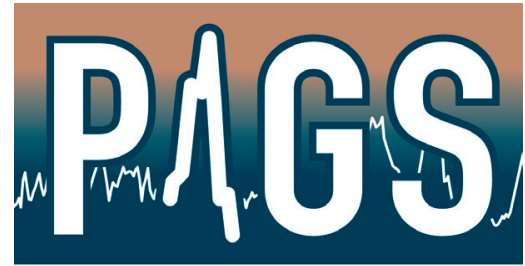

PAST INTERGLACIALS

Jerry F. McManus ${ }^{1}$, D. Raynaud ${ }^{2}$ and P.C. Tzedakis ${ }^{3}$

'Lamont-Doherty Earth Observatory of Columbia University, New York, USA; ${ }^{2}$ Laboratory of Glaciology and Geophysical Environment (LGGE), Grenoble, France; ${ }^{3}$ Department of Geography, University College London, UK; p.c.tzedakis@ucl.ac.uk

Uncertainties related to climate variability in a warming world lend high priority to studies of warm periods in the past. The interglacial intervals of the last 800 ka serve as particularly appropriate targets for such investigations (Tzedakis et al., 2009), as they represent the culmination of warming over a range of partially ice-free global climates. In order to help focus and coordinate international efforts to study these intervals, the PAGES Working Group on Past Interglacials (PIGS) held the third in a series of workshops at the Lamont-Doherty Earth Observatory of Columbia University.
Previous workshops laid out the PIGS themes and addressed intra-interglacial variability and interglacial onset. The meeting in New York brought together 30 scientists representing the marine, terrestrial, ice core and modeling communities to focus on interglacial duration (Fig. 1) and glacial inception. Participants came 
from 12 countries and included five postdoctoral investigators and five students.

The first day included a survey of interglacial duration based on different archives and climatic proxies. After an overview of insolation variations through time, a series of presentations reviewed the timing and duration of interglacials as viewed in climate records from ice cores, deep-sea sediments and terrestrial sequences. Presentations on ice cores focused on new chronologies, ultra-high resolution analyses, and the potential influence of atmospheric $\mathrm{CO}_{2}$ concentrations on interglacial length. Several speakers then discussed the timing and duration of sea level highstands as seen in deep-sea sediment and absolutely dated coral records. After a presentation on the interglacial hydrological cycle recorded in speleothem records, the day concluded with a poster session and group discussion of the session themes.

The second day featured presentations of data and modeling studies of glacial inception. These included ice core results from Greenland and Antarctica, and data from different interglacials and glacial inceptions in deep-sea cores from around the globe. A session on climate modeling included presentations on the influence of atmospheric $\mathrm{CO}_{2}$ concentrations and ocean circulation on the end of an interglacial, as well as attempts to incorporate the carbon cycle in climate modeling of the last interglacial and glacial inception. The day concluded with a discussion of the session themes and review of the Working Group progress.

The final day of the meeting centered on open discussions of issues related to the two primary topics. Although the participants noted that estimates and subsequent comparisons of interglacial durations are sensitive to the definition of interglacial conditions in each proxy and archive, and that the duration of any individual interglacial may vary in different proxies and different locations, they agreed that there are nevertheless valid and robust patterns that emerge among respective interglacials. Different intervals may be defined as short if they last no more than a few thousand years, intermediate if they last approximately ten thousand years, and long if their duration is tens of thousands of years. Similarly, the respective interglacials may be compared

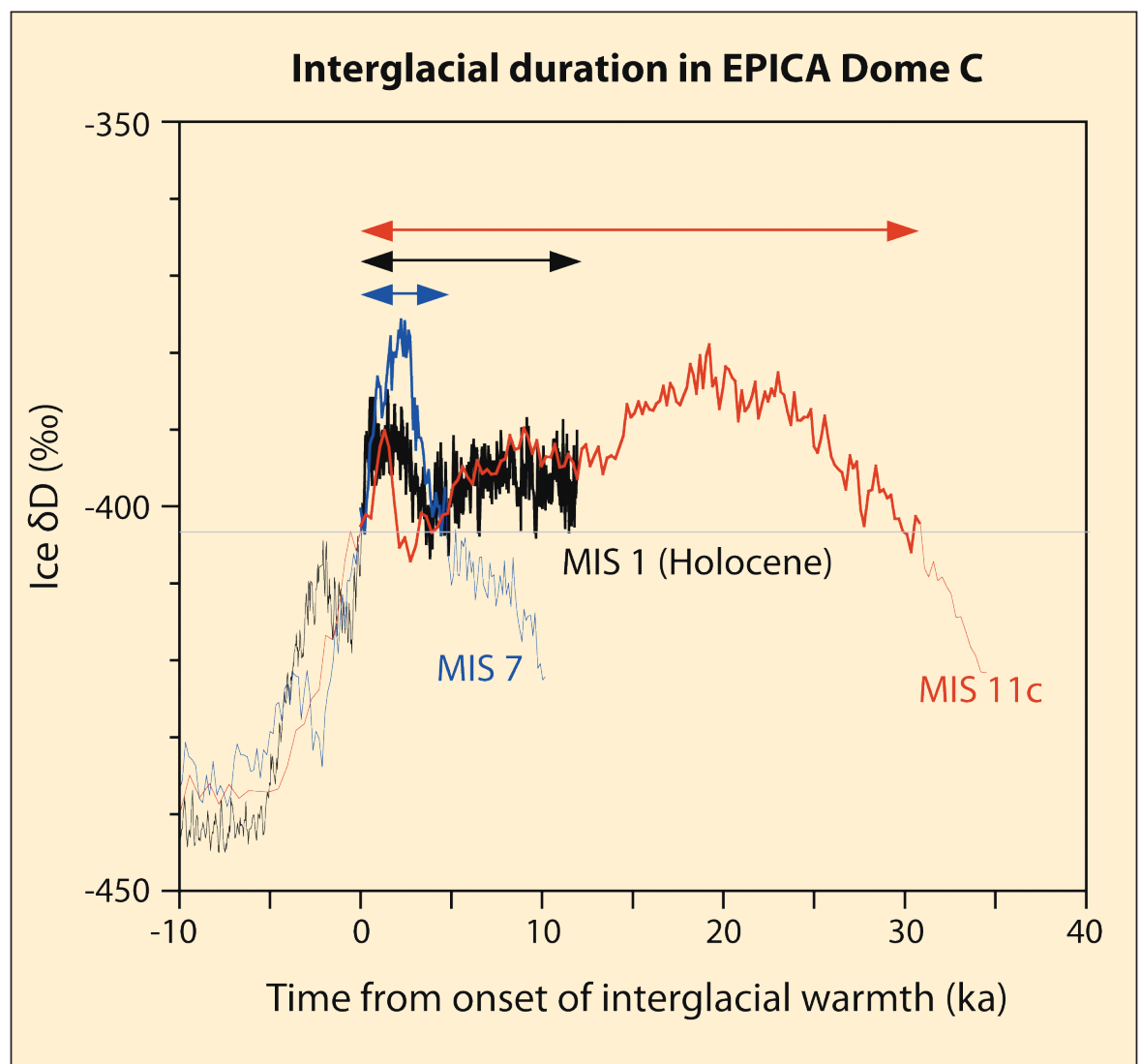

Figure 1: Examples of interglacial duration in an isotopic record from EPICA Dome C (Jouzel et al, 2007). For this illustration, the onset of interglacial warmth in Antarctica is defined by a threshold at -403 per mil in $\delta D$ (Wolff et al., 2004). By this metric, past interglacial intervals lasted $\sim 5,000$ years and $\sim 30,000$ years, while the Holocene duration is now approaching 12,000 years.

using various climatic indicators referenced to the Holocene and defined as short or long depending on that relationship. A subset of the Working Group was therefore assigned to lead and compare differences in the duration of past interglacials in a joint publication. The physics and forcing of the climate system that lead to those differences can then be explored in a more targeted way.

In contrast to interglacial durations, which may be estimated for any number of interglacials in a single long record and may differ among locations and climate indicators, the sequence of events associated with glacial inception should be globally coherent, and is best determined using multiple climate records from different locations and archives for a single interval. In this case, Working Group members agreed that a useful approach would be to summarize the global sequence of events that accompanied the last glacial inception, and a smaller group was assigned to lead the task of preparing a joint publication on this topic. This will allow gaps to be identified and addressed, and would provide a target for comparison with subsequent compilations of previous glacial inceptions. Improved absolute and relative chronological constraints are crucial to the successful evaluation of both interglacial duration and glacial inception, and so chronology was taken up as a third focal point to emerge from the workshop.

A fourth workshop, to be hosted by Chronis Tzedakis, will be held in the UK in July 2012. This meeting will focus on efforts to explain the structure of interglacials from the forcing, and will attempt to synthesize the various aspects of past interglacials addressed by the PIGS Working Group.

\section{References}

Jouzel, J., et al., 2007: Orbital and Millennial Antarctic Climate Variability over the Past 800,000 Years, Science, 317: 793-796.

Tzedakis, P.C., Raynaud, D., McManus, J.F., Berger, A., Brovkin, V. and Kiefer, T., 2009: Interglacial diversity, Nature Geoscience, doi: 10.1038/ngeo660.

Wolff, E. and EPICA community members, 2004: Eight glacial cycles from an Antarctic ice core, Nature, 429: 623-628. 